ence given to the feminine gender instead of, as in the more ungallant English, to the masculine; for instance, the word theirs translates " two hers." The work I present is necessarily but a chrestomalthy compared to what can be done in the study of each of the Iroquois languages. Enough beauties, however, have been discovered through this mere insight to convince one that their possibilities were great. The reflection is, therefore, sad that in all probability fifty years hence these chrestomalthics, imperfect as they are, may be the only record of their former existence. Even now English is fast becoming the cornmunicating medium of the people, as it is of the pulpit and the school. We can, therefore, safely predict that within the next certury the Iroquois languages, as spoken by its six different tribes, will have become a thing of the past.

\section{STRUCTURE OF MICA VEINS IN NORTH CAROLINA.}

BY W. C. KERR.

At Danville, Va., Professor Kerr, of Raleigh, found veins or dykes which seemed to have been filled neither by fused matter nor by the ordinary mode of infiltration, but by a fine granular fragmented mass, derived from the containing bedded rocks, by the crowding. jamming and mechanical comminution of the rocks themselves. The mica veins in North Carolina are simply dykes of very coarse yratnite. When the crystallization becomes so coilrse that the diameter of the mica sheets passes three or four inches, the dyke is called a mica vein. These veins are found in the upper Laurentian or Montalban, and may be considered characteristic of that horizon in North Carolina. The most productive veins are found in the high plateau between the Blue Ridge and the Smoky mountains, mostly in two or three counties. The amount of marketable mica produced per month is not more than two or three tons, although a much larger quantity could be obtained if the market de manded it. The most valuable of the present mica mines were opened and wrought by the mound-builders many ages ago on a much larger scale than now. There are evidences in the great river valleys in North Carolina of extensive glaciation in remote times, although the last glacial period is wholly unrepresented on the present surface. The protrusion of the enstern const of North Carolina, about a hundred miles beyond the general Atlantic coast, is due to the interaction of the Arctic shore current and the Gulf stream, which collect the detritus thrown into the sea from Maryland to South Carolina, and drop them about Hatteras. This action has carried the coast of North Carolina to within fifty miles of the margin of the deep Atlantic channel, and, therefore, near its limit. The sounds behind the chain of sand islands or dunes, known as "The Banks," are rapidly silted up and converted into marsh and dry lind by the sands blown over the dunes, and by the sediment brought down by the numerous rivers from the interior. The movement of the sand of these dunes was found to be about one foot per annum landward.

\section{TRANSFORMATION OF PLANORBIS.}

A PRACTICAL ILlustration OF the EVOLUtion OF SPECIES. BY A. HYATT.

The word evolution means the birth or derivation of one or more things or beings from others, through the action of natural laws. A child is evolved from its parents, a mineral from its constituents, a state of civilization from the conditions and surroundings of a preceding age. While evolution furnishes us with a valuable working hypothesis, science cannot forget that it is still on trial. The impatience of many when it is doubted or denied savors more of the dogmatism of belief than of the judicial earnestness of investigation. Every individual differs in certain superficial characters from the parent forms, but is still identical with hem in all its fundamental characteristics. This constantly recurring relationship among all creatures is the best estab. lished of all the laws of biology. It is the so-called law to heredity, that like tends to reproduce like. There seem to be only two causes which produce the variations which we observe; one is the law of heredity, the other is the surrounding influences or the sum of the physicial influences upon the organism. The first tends to preserve uniformity, the second modifies the action of the first. The law of natural selection asserts that some individuals are stronger or better fitted to compete with others, in the struggle of life, than are others of the same species : hence they will live and perpetuate their kind, while the others die out. An erroneous impression exists, that Darwinian doctrines are more or less supported by ali naturalists who accept evolution, but it is far from the truth. The Darwinian hypothesis is so very easy of application, and saves so much trouble in the way of investigation, that it is very generally employed, without the preliminary caution of a rigid analysis of the facts, and it is safe to say that it is often misap. plied. A great amount of nonsense has been written about its being a fundamental law, in all forgetfulness that we are yet to find a law for the origin of the variations upon witich it acts; it cannot be the primary cause of the variations, for the laws of heredity are still more fundamental. The speaker then described the situation and character of Steinheim, where numerous shells of the Planorbida are found in the strata, which have been very regularly depos. ited. Hlilgendorf claims to have discovered great evidences of the gradual evolution of the various forms from the sim. plest and oldest specimens, but Mr. Hyatt has failed to find whit Hilgendort describes. By means of a lantern a number of illustrations of the shells were projected upon a screen, and quite fully described. Four lines of descend. ants were shown to branch out from four of the simplest forms, with all the gaps between the species filled with intermediate varieties. Each one of the lines or series has its own set of characteristic differences, and its own peculiar history. It is a fair inference from the facts before us. that the species from the progressive series, which become largar and finer in every way, owe their increase in size to the favorable physical condition of the Steinheim basis. Darwinists would say that in the basin a battle had taken place, which only the favored ones survived. Mr. Hyatt endeavored to present, in a popular manner, the life-history of a single species, the planorbis licis, and its evolution into iwenty or thirty distinguishable forms, most of which may properly be called by different names and considered as distinct species. He also endeavored to bring the conception that the variations which led to these different species were due to the action of the laws of heredity, modified by physical forces, especially by the force of gravitation, into a tangible form. There are many characteristics which are due solely to the action of the physical influences which surround them; they vary with every change of locality, but remain quite constant and uniform within each.

\section{MOUNDS OF ILLINOIS}

BY W. MCAD.MS, OTTERVH.LE, I1.t.S.

Mr. McAdams stated that during a period of some as years, when leisure permitted, he had been exploring in the mounds of the State. Within a radius of 50 miles from the mouth of the Illinois river there were many thousands of mounds erected by the past inhabitants of the country.

A map was shown illustrating the ancient works of the region, which include almost every variety of mound in the Union. Mr. McAdams has explored hundreds of these mounds, and collected a great quantity of valuable material illustrating the habits and customs of the people of that age. He gave illustrations of House, Burial, Temple and other Mlounds.

Many of the small mounds in this section, the speaker thought, were the remains of dwelling places, originally made by placing poles on end, or in a vertical position fastened at the top, and the whole covered with sod and earth. This structure, after being repaired from year to year, would finally decar, fall to prices and form a mound. In many of these mounds he had found ashes, remains of animals eaten, and other articles that would be found in 